\title{
Research on the Influence of E-commerce service quality of fresh Agricultural products on customer satisfaction
}

\author{
$\mathrm{Xu}$ xin ${ }^{1, \mathrm{a}}$, Chen jiaying ${ }^{2, \mathrm{~b}^{*}}$ \\ ${ }^{1}$ Sichuan Agricultural University, Business School, Chengdu, Sichuan, China \\ ${ }^{2}$ Sichuan Agricultural University, Business School, Chengdu, Sichuan, China
}

\begin{abstract}
Analyzing the influence of service quality on customer satisfaction can help fresh e-commerce enterprises to better understand their own service level, formulate better service strategies and improve their competitive advantages, so as to promote the sustainable and healthy development of fresh e-commerce industry. In this paper, first of all, with the aid of web crawler, acquisition of jingdong mall fresh category contains fruit, vegetables, meat and seafood aquaculture 4 products on the number of online comments and evaluation star, and word frequency statistics and extract the data collected from online reviews of consumers to pay attention to the quality of service measures, after using qualitative analysis software - NVivo coding and grade, finally, the variable of descriptive statistics, correlation analysis and regression analysis. The results show that the tangibility, reliability, empathy and responsiveness of service quality have significant influence on customer satisfaction, and other evaluation indexes of guarantee quality have significant influence on customer satisfaction except delivery.
\end{abstract}

\section{Introduction}

Fresh agricultural products generally refer to primary agricultural products such as vegetables, fruits, meat and aquatic products, which are important components of agricultural products. At present, China's fresh ecommerce market is in a period of rapid development and popular with capital. Fresh e-commerce keeps improving all links of the industrial chain and the market performance is strong. According to the research Report on China's Fresh E-commerce Industry in 2019 released by Zhiyan Consulting, the transaction scale of China's fresh e-commerce market in 2018 exceeded 200 billion yuan, and it is expected that the fresh e-commerce industry will maintain an average annual growth rate of $35 \%$ in the next three years. At the same time, the habit of online shopping fresh has been formed, more than 60 percent of users online fresh more than once a week. However, with the rapid development of fresh e-commerce, there are also many difficulties. Fresh products have the characteristics of fresh activity and perishability, and bring customers extremely unstable experience, which puts forward higher requirements for e-commerce enterprises in supply chain, logistics storage, packaging and distribution, customer service and other aspects. Jingdong is a well-known comprehensive e-commerce platform in China, as well as an important sales platform for fresh agricultural products. Its scale of fresh agricultural products in the market is constantly expanding.

At present, researches on fresh e-commerce mainly focus on customers' purchase intention and satisfaction,

*Corresponding author: b191827098@qq.com

cold chain logistics and business model. In terms of customer satisfaction studied in this paper, the results show that service quality is an important factor affecting customer satisfaction. From the perspective of research models, some scholars have used The Chinese customer satisfaction index model, the expectation - performance theory model, the American customer satisfaction index model, the factor analysis model and the comprehensive customer satisfaction model to carry out researches, but none have used the SERVQUAL model to study the customer satisfaction of fresh e-commerce. From the source of data, most scholars use questionnaire survey to obtain data, while web crawler method to obtain data is still in its infancy. Therefore, based on SERVQUAL model, this paper obtained data through content analysis and studied the impact of fresh e-commerce on customer satisfaction, which is innovative to a certain extent.

Taking Jingdong as an example, this paper firstly crawled online reviews of 4 types of fresh agricultural products, and then carried out word frequency statistics and text analysis on the collected data to extract measurement indicators of service quality concerned by customers in online reviews, and carried out descriptive statistics, correlation analysis and regression analysis on variables. This article applies SERVQUAL model of fresh agricultural products online reviews research field, from the perspective of customers to generate the content of the service quality research, observation of different dimensions of service quality of customer satisfaction will be what impact, help to extension and complement of fresh electricity service quality research, is an optimum product for the electric business platform and fresh agricultural 
products business service provides the reference and help to fresh agricultural products the development of electricity industry.

Based on the service quality theory, this paper puts forward the hypothesis of its influence on customer satisfaction from the aspects of responsiveness, empathy, tangibility, reliability and guarantee.

H1: The tangibility of product and service quality will significantly affect the satisfaction of fresh e-commerce customers.

$\mathrm{H} 2$ : The guarantee of product and service quality will significantly affect the satisfaction of fresh e-commerce customers.

H3: The reliability of product service quality will significantly affect the satisfaction of fresh e-commerce customers.

H4: The empathy of product service will significantly affect the satisfaction of fresh e-commerce customers.

H5: The responsiveness of product and service quality will significantly affect the satisfaction of fresh ecommerce customers.

\section{Materials and Methods}

\subsection{Data collection}

The data of this study is from Jingdong Mall, and the acquisition date is April 2020. The octopus collector version 7.6.4 is adopted to obtain the original data of this study through custom collection. Considering the variety of fresh, online sales and number of comments, in order to make the data integrity and representative sample, in this paper, the jingdong fresh channel of fruits, vegetables, meat, seafood, aquatic four types of fresh produce sorted according to their respective sales and sales of the top 60 selected products, to obtain high praise, medium review and bad review of each product in the front page of a review and evaluation of the star number, total 7757 online comments. Due to the selectivity of crawler technology, the data involved in this study are current data. After that, the collected data was imported into the Excel table and strictly screened according to the text content to eliminate invalid, irrelevant and repetitive data, such as "this user did not fill in the evaluation content", "Ok bar" and other comments. Finally, 5070 comment data were obtained.

\subsection{Data preprocessing}

This paper explores the content of customer concerns from the review text, and reflects the different dimensions of product service quality, such as tangibility, assurance, reliability, empathy and responsiveness, and studies the relationship between service quality and customer satisfaction. First, all the comment text was consolidated into a single file, resulting in a total of over 420,000 words of comment content. Then the NLPIR of Chinese Word segmentation system of Chinese Academy of Sciences conducted word frequency statistics and extracted highfrequency words. After that, manual filtering was adopted to filter out the stopped words, and representative words were used to uniformly replace synonyms of similar texts.
A total of 129 high-frequency words (word frequency $\geq 20$ ) were obtained. These words are used to describe the packaging, logistics, taste, quality, etc. The frequency statistics of the top 10 words are as follows.

Table 1. Part of word frequency statistics

\begin{tabular}{|l|l|}
\hline High-frequency words & frequency \\
\hline fresh & 1108 \\
\hline packaging & 1018 \\
\hline delicious & 924 \\
\hline taste & 904 \\
\hline Courier & 877 \\
\hline On the palate & 633 \\
\hline Customer service & 610 \\
\hline logistics & 564 \\
\hline size & 493 \\
\hline The price & 479 \\
\hline
\end{tabular}

\subsection{Identification of influencing factors}

The high-frequency words were further sorted out, screened, refined and summarized, and 12 influencing factors were extracted according to the specific dimensions of SERVQUAL model, including safety guarantee, packaging, delivery, quantity, customer service attitude, taste, product description, after-sales, appearance, logistics, freshness and quality. The evaluation index distribution in the comment sample is shown in Table 2.

Table 2. Evaluation indexes

\begin{tabular}{|l|l|}
\hline The evaluation index & $\begin{array}{l}\text { Examples of high } \\
\text { frequency words }\end{array}$ \\
\hline taste (A1) & taste, mouthfeel \\
\hline fresh (A2) & fresh, tender \\
\hline quality (A3) & quality, bad \\
\hline security (B1) & guarantee, shelf life \\
\hline delivery (B2) & $\begin{array}{l}\text { delivery } \\
\text { delivery }\end{array}$ \\
\hline logistics (B3) & logistics, SF \\
\hline packaging (B4) & packing, packing bag \\
\hline commodity description (C1) & discrepancy, disparity \\
\hline appearance (C2) & size, fullness, \\
\hline weight (C3) & quantity, weight \\
\hline customer service attitude (D1) & $\begin{array}{l}\text { attitude, } \\
\text { attitude }\end{array}$ \\
\hline after-sales (E1) & $\begin{array}{l}\text { after-sales } \\
\text { return }\end{array}$ \\
\hline
\end{tabular}

\subsection{Quantitative coding of comment text}

In order to further analyze the relationship between the five dimensions of service quality and customer satisfaction, this paper determined the evaluation indexes of each dimension, coded each comment according to the evaluation indexes, and gradually transformed qualitative data into quantitative data. Likert scale was used to divide each factor into 5 levels, namely, very dissatisfied, relatively dissatisfied, general, relatively satisfied and 
very satisfied, corresponding to $1,2,3,4$ and 5 respectively. The factor not mentioned in the online review indicates the customer's neutral feeling and is therefore coded as 3 .

\section{Results \& Discussion}

After text analysis, the evaluation index of service quality in online comments is mined, which is taken as the independent variable of this study, and the number of evaluation stars climbed is taken as the dependent variable of this study, so as to construct the research model of this paper and observe the influence of service quality on customer satisfaction. In the context of online shopping, this paper takes four types of fresh agricultural products as the research subject. The inherent characteristics of fresh agricultural products and service characteristics of products are important factors affecting customer satisfaction.

This paper aims to explore the impact of the service quality of products reflected in online reviews on customer satisfaction. Based on service quality theory and the above literature review, with taste, freshness and quality to measure the tangibility of service quality, with a security guarantee, packing, delivery, logistics as a guarantee measure, the description of commodity, appearance and weight as indicators of quality of service reliability, using online reviews of customer service attitude to measure the service quality of empathy, will sell later measure of the responsiveness of service quality. According to the definition of quality of service, variables are described as follows.

Table 3. Variable description

\begin{tabular}{|l|c|c|}
\hline \multirow{2}{*}{ variable } & $\begin{array}{c}\text { Service quality } \\
\text { dimension }\end{array}$ & $\begin{array}{c}\text { The evaluation } \\
\text { index }\end{array}$ \\
\hline \multirow{3}{*}{$\begin{array}{l}\text { independent } \\
\text { variables }\end{array}$} & tangibility & $\mathrm{A} 1, \mathrm{~A} 2, \mathrm{~A} 3$ \\
\cline { 2 - 3 } & guarantee & $\mathrm{B} 1, \mathrm{~B} 2, \mathrm{~B} 3, \mathrm{~B} 4$ \\
\cline { 2 - 3 } & reliability & $\mathrm{C} 1, \mathrm{C} 2, \mathrm{C} 3$ \\
\cline { 2 - 3 } & empathy & $\mathrm{D}$ \\
\cline { 2 - 3 } $\begin{array}{l}\text { dependent } \\
\text { variable }\end{array}$ & $\begin{array}{c}\text { customer } \\
\text { satisfaction }(\mathrm{Y})\end{array}$ & $\begin{array}{c}\text { Evaluation star } \\
\text { number }\end{array}$ \\
\hline
\end{tabular}

\subsection{Descriptive Statistics}

Variables of descriptive statistics as shown in table 5, it can be seen that flavor, fresh taste, shipping, logistics, packaging is greater than the average of 3 , showed the customer to review positive end to these factors, and to the quality of the average value is less than 3, product description, appearance, weight, after the negative evaluation, security and customer service attitude towards average equals 3 comments are somewhere in the middle position.

Table 4. describes the statistics

\begin{tabular}{|l|l|l|l|l|l|}
\hline & $\mathbf{N}$ & $\mathbf{m i n}$ & $\mathbf{m a x}$ & mean & $\begin{array}{l}\text { Standard } \\
\text { Deviation }\end{array}$ \\
\hline $\mathrm{A} 1$ & 5070 & 1 & 5 & 3.18 & 1.028 \\
\hline $\mathrm{A} 2$ & 5070 & 1 & 5 & 3.08 & .684 \\
\hline $\mathrm{A} 3$ & 5070 & 1 & 5 & 2.69 & .984 \\
\hline $\mathrm{B} 1$ & 5070 & 1 & 5 & 3.00 & .322 \\
\hline B2 & 5070 & 1 & 5 & 3.02 & .339 \\
\hline $\mathrm{B} 3$ & 5070 & 1 & 5 & 3.25 & .970 \\
\hline $\mathrm{B} 4$ & 5070 & 1 & 5 & 3.11 & .809 \\
\hline $\mathrm{C} 1$ & 5070 & 1 & 5 & 2.92 & .465 \\
\hline $\mathrm{C} 2$ & 5070 & 1 & 5 & 2.97 & .797 \\
\hline $\mathrm{C} 3$ & 5070 & 1 & 5 & 2.98 & .532 \\
\hline $\mathrm{D} 1$ & 5070 & 1 & 5 & 3.00 & .394 \\
\hline E1 & 5070 & 1 & 5 & 2.91 & .537 \\
\hline $\mathrm{Y}$ & 5070 & 1 & 5 & 3.13 & 1.657 \\
\hline $\mathrm{N}$ & 5070 & & & & \\
\hline
\end{tabular}

\subsection{Correlation analysis}

The correlation between variables is shown in Table 5. It can be seen that the correlation coefficient between each variable is less than 0.5 , so the correlation or collinearity between variables is not strong. In addition, the largest variance inflation factor VIF in the independent variable was 1.190 , far less than 10 , and the average VIF of all variables was not significantly greater than 1 . Therefore, there is no serious multicollinearity problem in this model.

Table 5. Correlation statistics

\begin{tabular}{|l|l|l|l|l|l|l|l|l|l|l|l|l|l|l|}
\hline & VIF & 1 & 2 & 3 & 4 & 5 & 6 & 7 & 8 & 9 & 10 & 11 & 12 & 13 \\
\hline A1 & 1.130 & 1 & & & & & & & & & & & & \\
\hline A2 & 1.113 & .210 & 1 & & & & & & & & & & & \\
\hline A3 & 1.121 & .185 & .176 & 1 & & & & & & & & & & \\
\hline B1 & 1.022 & .059 & .068 & .063 & 1 & & & & & & & & & \\
\hline B2 & 1.038 & .081 & .053 & .116 & .033 & 1 & & & & & & & & \\
\hline B3 & 1.190 & .198 & .187 & .224 & .090 & .127 & 1 & & & & & & & \\
\hline B4 & 1.141 & .194 & .154 & .152 & .117 & .083 & .274 & 1 & & & & & & \\
\hline C1 & 1.029 & .096 & .061 & .043 & .009 & .049 & .082 & .087 & 1 & & & & & \\
\hline C2 & 1.094 & .177 & .189 & .120 & .055 & .048 & .168 & .150 & .108 & 1 & & & & \\
\hline C3 & 1.034 & .097 & .080 & .081 & .030 & .046 & .113 & .099 & .070 & .104 & 1 & & & \\
\hline D1 & 1.069 & .065 & .066 & .102 & .012 & .110 & .124 & .093 & .065 & .063 & .039 & 1 & & \\
\hline E1 & 1.077 & .084 & .063 & .152 & .045 & .062 & .140 & .083 & .049 & .071 & .065 & .204 & 1 & \\
\hline Y & & .494 & .339 & .480 & .133 & .138 & .399 & .333 & .192 & .295 & .207 & .191 & .264 & 1 \\
\hline
\end{tabular}




\subsection{Regression analysis}

Based on the data of quantitative coding, this paper takes 12 indicators of tangibility, assurance, reliability, empathy and responsiveness as independent variables and customer satisfaction as dependent variables to conduct regression analysis. The results are shown in Table 7. It can be seen that the goodness of fit of the model is 0.554 , and the adjusted goodness of fit is 0.553 , indicating that the model is acceptable. In addition, except for the significance level of delivery of 0.15 which is greater than 0.05 , the significance level of all the other factors is far less than 0.05 , indicating that the remaining factors have a significant impact on customer satisfaction.

Table 6. Regression analysis

\begin{tabular}{|l|l|l|l|l|}
\hline variable & $\begin{array}{l}\text { regression } \\
\text { coefficient }\end{array}$ & $\begin{array}{l}\text { Standard } \\
\text { Deviation }\end{array}$ & t & Sig. \\
\hline (constant) & -7.441 & .255 & -29.148 & .000 \\
\hline A1 & .494 & .016 & 30.711 & .000 \\
\hline A2 & .312 & .024 & 13.012 & .000 \\
\hline A3 & .501 & .017 & 29.936 & .000 \\
\hline B1 & .231 & .049 & 4.721 & .000 \\
\hline B2 & .067 & .047 & 1.438 & .150 \\
\hline B3 & .258 & .017 & 14.724 & .000 \\
\hline B4 & .232 & .021 & 11.283 & .000 \\
\hline C1 & .326 & .034 & 9.606 & .000 \\
\hline C2 & .217 & .020 & 10.599 & .000 \\
\hline C3 & .265 & .030 & 8.920 & .000 \\
\hline D1 & .255 & .041 & 6.255 & .000 \\
\hline E1 & .376 & .030 & 12.493 & .000 \\
\hline
\end{tabular}

a. Dependent variable: Satisfaction

Note: $\mathrm{R}^{2}=0.554$, adjusted $\mathrm{R}^{2}=0.553$

\section{Conclusions}

This research use octopus collector from jingdong mall to vegetables, fruits, meat, seafood, aquatic 7757 online review of four types of fresh agricultural products, through artificial selection to eliminate invalid, repetition, meaningless comments after leaving 5070 data, with the Chinese Academy of Sciences, Chinese word segmentation system NLPIR participle and word frequency statistics to identify the customer focus on the main factors, the factors are classified according to the service quality model, is divided into five dimensions of evaluation indexes. Then, NVivo11 is used to encode the comment text, transform the qualitative comment text into quantitative data, and conduct descriptive statistical analysis, correlation analysis and multiple regression analysis.

It can be seen from the results that the tangibility of service quality of fresh agricultural products significantly affects customer satisfaction, that is, the better the taste, freshness and quality of fresh agricultural products, the higher customer satisfaction. As for the guarantee of service quality of fresh agricultural products, in addition to delivery, safety guarantee, logistics and packaging all have a significant impact on customer satisfaction, that is, delivery speed has little impact on customer satisfaction. The reliability of service quality of fresh agricultural products has a significant impact on customer satisfaction, that is, the consistency between the actual products online shopping and the picture description, the consistency between the quantity and appearance will make customers feel the integrity and reliability of the merchants, so as to enhance customer satisfaction. Empathy of service quality of fresh agricultural products significantly affects customer satisfaction, that is, the more patient and thoughtful the customer service attitude, the higher customer satisfaction. The responsiveness of service quality of fresh agricultural products has a significant impact on customer satisfaction, even if the customer service staff timely communicate and solve problems in the after-sales process, the customer will be satisfied.

In view of the research conclusion, this paper puts forward the following Suggestions. First, pay attention to quality control and improve the tangible service quality. Customers of fresh agricultural products pay attention to the taste, freshness and quality of products in the process of online shopping. Merchants and platforms can only deliver good products to customers as far as possible if they check the products at the source and do a good job in strict selection during procurement and quality inspection before delivery. Second, improve the level of logistics, improve the guarantee of service quality. Strengthen the construction of the cold chain logistics system of the platform, and constantly develop new packaging materials and packaging methods to ensure that products reach customers quickly, efficiently and intact. Third, pay attention to the construction of good faith, improve the reliability of service quality. Merchants and platforms should try their best to describe the products, such as the appearance and net weight of the products, so that customers can get real information and choose satisfactory products. Fourthly, strengthen customer service training to improve the empathy and responsiveness of service quality. Regular customer service training, so that professional high quality customer service in the process of communication with customers to maintain a warm attitude, timely and efficient solution to after-sales problems, to provide customers with satisfactory solutions.

\section{References}

1. Parasuraman,A., Zeithaml Valarie ,A., Berry Leonard,L.(1988) SERVQUAL: A Multiple-Item Scale for Measuring Consumer Perceptions of Service Quality. Journal of Retailing, 64(1): 12-40.

2. Zhang,H.X.(2019) Influencing Factors of Consumer Satisfaction of Fresh Agricultural Products in Ecommerce -- An Exploration and analysis based on online comments. Jiangsu Agricultural Science, 47(17):4-8.

3. Wang,G.N.(2018) Empirical Research on influencing factors of consumers' satisfaction with fresh agricultural products purchased online. Journal of Commercial Economics, 06: 47-49.

4. Zhou,T.,Lu,Y.B.(2007)Research on consumers' Online 
repetitive shopping Behavior based on SERVQUAL.

Journal of Management Science, 03: 61-67. 